\section{Bioética no amparo aos idosos na carência e na enfermidade}

Pimentel, Willian

Grupo de Estudos e Pesquisa em Bioética do Centro Universitário Newton Paiva - GEPBio. e-mail: willianpimentel.ef@gmail.com.

\section{Gustin, Clara de Sousa}

Grupo de Estudos e Pesquisa em Bioética do Centro Universitário Newton Paiva - GEPBio.

\author{
Sarsur, Marcelo \\ Grupo de Estudos e Pesquisa em Bioética do Centro \\ Universitário Newton Paiva - GEPBio.

\section{Dadalto, Lucina} \\ Grupo de Estudos e Pesquisa em Bioética do Centro \\ Universitário Newton Paiva - GEPBio.
}

PALAVRAS-CHAVE: Idosos, Abandando, Solidariedade, Afetividade, Bioética

O objetivo da presente pesquisa é verificar a aplicação dos princípios da dignidade da pessoa humana, da solidariedade familiar e da afetividade, em relação à pessoa idosa, principalmente em situação de abandono. Conforme previsto nos artigos 229 e 230 da Constituição Federal de 1988, os deveres de cuidado e amparo recíprocos devem existir nas relações entre os jovens e os idosos, o que também está previsto, infraconstitucionalmente no Estatuto do Idoso (Lei $\left.n^{0} 10.741 / 2003\right)$, que dispõe em seu art. 98 a criminalização do abandono de idoso em hospitais, entidades de longa permanência ou outras espécies de casas de saúde. Esse tema se torna relevante devido ao envelhecimento da população brasileira ser um fenômeno contemporâneo, alicerçado nos avanços da medicina, da farmacologia e na relativa proteção jurídica da população idosa. Segundo dados do Instituto Brasileiro de Geografia e Estatística, no ano de 2012 o Brasil possuía 25,4 milhões de idosos e em 2017 o número de pessoas com mais de 60 anos ultrapassou os 30,2 milhões. Dados fornecidos pelo Instituto de Pesquisa Econômica Aplicada (IPEA), destacam que até o ano de 2050, esse grupo etário deve totalizar em torno de 68,1 milhões de pessoas. Importante perceber que países como populações envelhecidas, como Alemanha e Japão vêm promovendo políticas públicas para o enfrentamento dos diversos aspectos que interferem em um envelhecimento ativo. Nesse contexto indaga-se a necessidade de o Brasil adotar tais modelos e implementar políticas públicas com vistas à melhoria na qualidade de vida da população idoso, pois em referencial literário, o que se observa, é o aumento dos casos de abandono e maus tratos, contrariando os preceitos éticos, bioéticos e jurídicos. Tais fatos ocorrem, inclusive, em unidades hospitalares, o que é justificado pela literatura como o papel desempenhado pelo idoso na família e na comunidade, normalmente atrelado à trabalho, despesas e fardo. Diante desse cenário de negligência familiar e social, conclui-se que há necessidade de devida aplicação dos dispositivos já existentes, de modificação da legislação vigente, a bem como orientação às equipes de saúde, dentro dos preceitos da bioética, para que o idoso, tendo em vista sua vulnerabilidade, tenha respeitada a sua dignidade durante o tratamento de eventuais enfermidades.

AGRADECIMENTOS. Agradecemos a todos que de alguma forma contribuíram para a realização desta pesquisa, mesmo com toda a dificuldade encontrada para produção acadêmica científica nesse país. Em especial aos Coordenadores do GEPBio, por acreditarem no nosso potencial.

\section{REFERÊNCIAS:}

[1] STATISTISCHES BUNDESAMT. GENESIS-Online https:/www.destatis.de/DE/Startseite.html. Acesso em: 25. Set. 2018

[2] BRASIL. Instituto Brasileiro de Geografia e Estatística Disponível em: https://www.ibge.gov.br/apps/populacao/projecao/. Acesso em: 25. Set. 2018

[3] BRASIL.Constituição da República Federativa do Brasil. Disponível em: http://www.planalto.gov.br/ccivil 03/constituicao/constituica ocompilado.htm Acesso em: 20 set. 2018

[4] BORGES, Jackeline Gomes. Fatores associados à reospitalização em idosos com doenças crônicas acompanhados em programa de atenção domiciliar. 2018. 75 f. Dissertação (Mestrado em Saúde Coletiva) - Universidade Federal de Goiás, Goiânia, 2018.

[5] BRASIL. Lei 10.741 de $1^{\circ}$ de Outubro de 2003 - Estatuto do Idoso. Disponível em: http://www.planalto.gov.br/ccivil 03/LEIS/2003/L10.741.ht m. Acesso em: 25. Set. 2018. 